\title{
Front Matter: Volume 9295
}

, "Front Matter: Volume 9295," Proc. SPIE 9295, International Symposium on Optoelectronic Technology and Application 2014: Laser Materials Processing; and Micro/Nano Technologies, 929501 (18 December 2014); doi: $10.1117 / 12.2180277$

SDIE Event: International Symposium on Optoelectronic Technology and SPIE. Application 2014, 2014, Beijing, China 


\title{
PROCEEDINGS OF SPIE
}

\section{International Symposium on Optoelectronic Technology and Application 2014 \\ Laser Materials Processing; and Micro/Nano Technologies}

\author{
Norbert Kaiser \\ Bincheng Li \\ Yiqin Ji \\ Geert Verhaeghe \\ Minlin Zhong \\ Binghen Lu \\ Editors \\ Huaming Wang \\ Ming C. Leu \\ Yongnian Yan \\ Huikai Xie \\ Dawei Zhang \\ Guangya Zhou
}

\section{3-15 May 2014 \\ Beijing, China}

Organized by

Photoelectronic Technology Committee, Chinese Society of Astronautics (China)

Sponsored by

Chinese Society of Astronautics (China)

China High-tech Industrialization Association (China)

Technical Cosponsor and Publisher

SPIE 
The papers included in this volume were part of the technical conference cited on the cover and title page. Papers were selected and subject to review by the editors and conference program committee. Some conference presentations may not be available for publication. The papers published in these proceedings reflect the work and thoughts of the authors and are published herein as submitted. The publisher is not responsible for the validity of the information or for any outcomes resulting from reliance thereon.

Please use the following format to cite material from this book:

Author(s), "Title of Paper," in International Symposium on Optoelectronic Technology and Application 2014: Laser Materials Processing; and Micro/Nano Technologies, edited by N. Kaiser, B. Li, Y. Ji, G. Verhaeghe, M. Zhong, B. Lu, H. Wang, M. C. Leu, Y. Yan, H. Xie, D. Zhang, G. Zhou, Proceedings of SPIE Vol. 9295 (SPIE, Bellingham, WA, 2014) Article CID Number.

ISSN: 0277-786X

ISBN: 9781628413816

Published by

SPIE

P.O. Box 10, Bellingham, Washington 98227-0010 USA

Telephone +1 3606763290 (Pacific Time) · Fax +1 3606471445

SPIE.org

Copyright (C) 2014, Society of Photo-Optical Instrumentation Engineers.

Copying of material in this book for internal or personal use, or for the internal or personal use of specific clients, beyond the fair use provisions granted by the U.S. Copyright Law is authorized by SPIE subject to payment of copying fees. The Transactional Reporting Service base fee for this volume is $\$ 18.00$ per article (or portion thereof), which should be paid directly to the Copyright Clearance Center (CCC), 222 Rosewood Drive, Danvers, MA 01923. Payment may also be made electronically through CCC Online at copyright.com. Other copying for republication, resale, advertising or promotion, or any form of systematic or multiple reproduction of any material in this book is prohibited except with permission in writing from the publisher. The CCC fee code is 0277-786X/14/\$18.00.

Printed in the United States of America.

Publication of record for individual papers is online in the SPIE Digital Library.

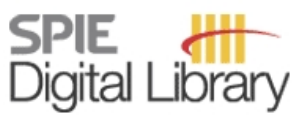

SPIEDigitalLibrary.org

Paper Numbering: Proceedings of SPIE follow an e-First publication model, with papers published first online and then in print and on CD-ROM. Papers are published as they are submitted and meet publication criteria. A unique, consistent, permanent citation identifier (CID) number is assigned to each article at the time of the first publication. Utilization of CIDs allows articles to be fully citable as soon as they are published online, and connects the same identifier to all online, print, and electronic versions of the publication. SPIE uses a six-digit CID article numbering system in which:

- The first four digits correspond to the SPIE volume number.

- The last two digits indicate publication order within the volume using a Base 36 numbering

system employing both numerals and letters. These two-number sets start with 00, 01, 02, 03, 04, $05,06,07,08,09,0 A, 0 B \ldots$. 0Z, followed by 10-1Z, 20-2Z, etc.

The CID Number appears on each page of the manuscript. The complete citation is used on the first page, and an abbreviated version on subsequent pages. Numbers in the index correspond to the last two digits of the six-digit CID Number. 


\title{
Contents
}

\author{
vii Authors \\ ix Symposium Committees \\ xiii Conference Committee \\ $\mathrm{xv}$ Introduction
}

VACUUM MANUFACTURING, OPTICAL THIN FILM AND SURFACE CHARACTERIZATION TESTING TECHNOLOGY

929502 Research on reverse association mechanism of the thermal control performance of conducting optical solar reflector and its antistatic properties [9295-102]

929503 Depth profile analysis of native oxide layer on GaAs (100) surface [9295-103]

929504 Theoretical and experimental analysis of optical gyroscopes based on fiber ring resonators [9295-104]

929505 Physical properties of ITO thin films prepared by ion-assisted electron beam evaporation [9295-105]

929506 Optical characteristics and damage thresholds of mirror in RLG dither [9295-106]

929507 The design and fabricate of wide angle $905 \mathrm{~nm}$ narrow band filter [9295-108]

929508 Infrared transparent conductive films [9295-109]

929509 In-situ and real time stress of $30.4 \mathbf{n m ~ M o / S i ~ m u l t i l a y e r ~ m i r r o r ~ f o r ~ t h e ~ m o o n - b a s e d ~ E U V ~}$ Camera [9295-110]

9295 OA High-reflectance of hybrid reflector with distributed Bragg reflector and metal mirror for flip-chip ultra-violet light-emitting diodes [9295-1 12]

9295 OB Analysis of influence of wrinkled surface on scattering characteristics [9295-114]

\section{LASER MATERIALS PROCESSING AND MICRO-NANO FABRICATION}

9295 OC 35CrMo steel surface by laser cladding Fe-based WC composite coating performance analysis [9295-202]

9295 OD Improvement on ball-milling composite process of metal matrix micro-nanometer powder using nanosuspension as the precursor [9295-204] 
9295 OE The study of laser plasma plume radiation produced by laser ablation of silicon [9295-205]

$9295 \mathrm{OF}$ Preparation and spectral properties of $\mathrm{Ho}^{3+} / \mathrm{Tm}^{3+} \mathrm{co}-\mathrm{doped}$ Germanium glass active optical fiber material [9295-206]

$9295 \mathrm{OH} \quad$ Process of super-black shading material applied to the star sensor based on Ni-P alloys [9295-209]

92950 Ol Sub-wavelength surface structuring on stainless steel by femtosecond laser pulses [9295-210]

9295 OK Temperature and thermal stress fields during the pulse train of long-pulse laser irradiating aluminium alloy plate [9295-216]

$9295 \mathrm{OL} \quad$ High repetition-rate and short pulse-width $1064 \mathrm{~nm}$ laser in a composite crystal device [9295-217]

$92950 \mathrm{M} \quad$ Research on the thermal effect of copper between adjacent pulses under moving laser irradiation [9295-218]

9295 ON Numerical analysis of thermal effect in aluminum alloy by monopulse laser [9295-220]

929500 Thermal stress simulation of multi-pulse laser irradiate on fused silica [9295-221]

9295 OP Numerical simulation for influence of pulse width on the temperature field of unidirectional carbon fiber [9295-226]

$92950 Q \quad$ Theoretical simulation of melt ejection during the laser drilling process on aluminum alloy by single pulsed laser [9295-227]

9295 OR Investigation on the defect structure and optical damage resistance of In:Tm:LiNbO 3 crystals with different doping concentrations of $\operatorname{In}^{3+}$ [9295-229]

9295 OS Analysis of thermodynamic effect in Si irradiated by pulsed-laser [9295-240]

9295 OT Study and design of beam expander with wide aperture [9295-242]

9295 OU Study on temperature distribution characteristics of alumina irradiating by irregular laser [9295-243]

9295 OV Infrared thermography processing using Markov-PCA algorithm [9295-245]

9295 OW Widely tunable mid-infrared optical parametric oscillator based on a multiple periods MgO:PPLN [9295-252]

9295 0X Research of the optical structure for a handled laser-cleaner [9295-258]

9295 OY Laser shock microforming of aluminum foil with fs laser [9295-259]

$92950 Z$ The application of hand-held laser wire stripper in the field of aerospace [9295-260] 
929510 Design and direct manufacture of non-assembly abacus by Selective Laser Melting [9295-304]

$929511 \quad$ Numerical analysis for search-based intra-cavity beam cleanup system [9295-307]

929512 Room temperature operation of $2.67 \mathrm{~mJ}$ pulse LD end pumped Q-switched Im:YAG laser [9295-303]

929513 A novel method for fabricating curved frequency selective surface via 3D printing technology [9295-301]

\section{MICRO/NANO OPTICAL TECHNOLOGY AND APPLICATION}

929514 Wavelength properties of DCG holograms under the conditions of different temperature and humidity [9295-311]

929515 The preparation and application of white graphene [9295-511]

929516 Three-peak standard white organic light-emitting devices for solid state lighting [9295-211]

929517 Non-isothermal molding technology research of ultra-precision glass lens [9295-611]

929518 Dynamic modulation of slow light by electro-optic effect in photonic crystal coupled resonator optical waveguide [9295-411] 
Proc. of SPIE Vol. $9295929501-6$

Downloaded From: https://www.spiedigitallibrary.org/conference-proceedings-of-spie on 26 Apr 2023 Terms of Use: https://www.spiedigitallibrary.org/terms-of-use 


\section{Authors}

Numbers in the index correspond to the last two digits of the six-digit citation identifier (CID) article numbering system used in Proceedings of SPIE. The first four digits reflect the volume number. Base 36 numbering is employed for the last two digits and indicates the order of articles within the volume. Numbers start with 00, 01, 02, 03, 04, 05, 06, 07, 08, 09, OA, OB...0Z, followed by 10-1Z, 20-2Z, etc.

\begin{tabular}{|c|c|}
\hline Cai, Ji-xing, 0O, OT & Liang, Fengchao, 13 \\
\hline Cao, Jian-lin, 09 & Lin, Haipeng, Ol \\
\hline Chang, Tianhai, 02 & Liu, Fengdeng, $\mathrm{OH}$ \\
\hline Chen, Bo, 09 & Liu, Jia, OX \\
\hline Chen, Chang, 03 & Liu, Ruicheng, 10 \\
\hline Chen, Guibo, ON & Liu, WenJin, 11 \\
\hline Chen, ShanQiu, 11 & Liu, Xiaoxi, $\mathrm{OZ}$ \\
\hline Chen, Xin-yu, OW, 12 & Liu, Yang, 10 \\
\hline Chen, Yong, 06 & Liu, Yao-ying, 04 \\
\hline Cheng, Hongchang, 03 & Liu, Yujie, 14 \\
\hline Cheng, Man, OD & Ma, Yao, OP, OS \\
\hline Cheng, Xing, 03 & Mao, Hongxia, OB \\
\hline Cui, Dan-feng, 04 & Miao, Zhuang, 03 \\
\hline Cui, Xiao-wen, 04 & Niu, Sen, 03 \\
\hline Ding, Quanxin, 14 & Pan, Li, OV \\
\hline Dong, LiZhi, 11 & Qi, Litao, Ol \\
\hline Fan, Chuanhui, ou & Qin, Hengfeng, OC \\
\hline Feng, Yayun, OY & Qiu, Yang, 05 \\
\hline Gao, C.M., OF & Qu, Yi, 07 \\
\hline Gao, Jie, OR & Shen, Qing, OD \\
\hline Gao, Jinsong, 13 & Shi, Baohua, 07 \\
\hline Gu, Xiu-ying, OK, ON, OQ & Shi, Feng, 03 \\
\hline Guo, Kunping, 16 & Song, Changhui, 10 \\
\hline Guo, Ming, OO, OQ, OS, ОТ & Song, Xuedi, 12 \\
\hline Guo, Y.Y., OF & Sun, Wei-guo, 08 \\
\hline Han, K. X., OF & Tan, F., OF \\
\hline He, Fei, 09 & Tang, Qingju, OV \\
\hline He, Xing, 11 & Tao, Bo, 17 \\
\hline He, ZheXi, OX & Tao, Fei, 08 \\
\hline Hu, Jinping, 0 & Tong, Jianqiang, OR \\
\hline Hu, Yan, 11 & Wan, Yong, 18 \\
\hline Hua, Xijun, OY & Wang, Chao, ow \\
\hline Hua, Yinqun, OY & Wang, Di, OM, OP, OQ, OU \\
\hline Huang, Huamao, OA & Wang, $\mathrm{Di}, 10$ \\
\hline Huang, Qingju, OE & Wang, Hai-feng, 09 \\
\hline Huang, Zhen, OR & Wang, Hong, OA \\
\hline Jin, Guang-yong, OK, OL, OM, ON, OO, OP, OQ, OS, & Wang, Hongyu, OD \\
\hline OT, OU, OW, 12 & Wang, J., OF \\
\hline Jin, Yangli, 05 & Wang, Jiajia, 05 \\
\hline Li, Changhong, 18 & Wang, Jiliang, 06 \\
\hline Li, Hongtao, OV & Wang, Jilin, $\mathrm{OZ}$ \\
\hline Li, Hongyu, 07 & Wang, JunLong, OX \\
\hline Li, Mingxin, ON, OQ, OS & Wang, L. L., OF \\
\hline Li, Wenqiang, 14 & Wang, Li-wen, 08 \\
\hline Li, Xiangfeng, OD & Wang, Lei, OV \\
\hline Li, Yan-na, 04 & Wang, Long, 03 \\
\hline Li, Yinliang, 06 & Wang, Xiao-dong, 09 \\
\hline Li, Yun-peng, 09 & Wang, Xiao-duo, 09 \\
\hline Li, Zaijin, 07 & Wang, Xuefeng, OX \\
\hline
\end{tabular}


Wang, Yong-hua, 04

Wang, Zijian, OL

Wei, Bin, 16

Wei, Guang, 06

Wei, Li-ping, 04

Wei, Xiaoqun, 02

Wei, Zhi, OM, OP, OT, OU

Wu, Chun-ting, OW, 12

Wu, Kaifeng, OB

Wu, Shuling, 02

Wu, Yuelong, $\mathrm{OH}$

Xiao, Zefeng, 10

Xing, Fei, $\mathrm{OH}$

Xing, Hualu, Ol, OV

Xing, Zheng, 02

$\mathrm{XU}$, Bing, 11

$\mathrm{Xu}, \mathrm{BO}, 05$

$X U$, Zhaopeng, OR

Xuan, Ting, OY

Xue, Chen-yang, 04

Xue, Qingyun, 06

Yan, Zhanjun, 14

Yang, Guang, OA

Yang, Hua-bin, 09

Yang, Ping, 11

Yang, Yongqiang, 10

Ye, Yunxia, OY

You, Zheng, $\mathrm{OH}$

YU, F. X., OF

Yu, Hua-dong, OM, 0O, OS

Yu, Jiaxin, 17

Yu, Kai, 12

Yu, Ruitao, 18

Yu, WenPeng, OX

Yu, Yongji, OL

Yu, Yong-ji, OW

Yuan, Boshi, OM, OP, OS, OU

Zang, Hongbin, 17

Zhai, Rui-zhi, OL, OW

Zhang, Haomin, OC

Zhang, Hong-ji, 09

Zhang, Lei, 08

Zhang, Liang, 08

Zhang, Wei, OK, ON, OT

Zhang, Xiaoling, OR

Zhang, Xin, OR

Zhao, EnYi, 11

Zhao, Hua, 05

Zhao, Jianlin, 06

Zhao, Jing, OW

Zheng, Li, OB

Zheng, Xin, 09

Zhou, Chenghong, 15

Zhou, Houming, OC

Zhou, Jianzhong, OD

Zhou, Yingyue, 17

Zhu, Xu-bo, 08 


\title{
Symposium Committees
}

\author{
Symposium Chairs
}

Guofan Jin, Tsinghua University (China)

Songlin Zhuang, University of Shanghai for Science and Technology (China)

\section{Conference Committee}

Bingheng Lu, Xi'an Jiaotong University (China)

Byoungho Lee, Seoul National University (Republic of Korea)

Daren Lv, Institute of Atmospheric Physics (China)

David Webb, Aston University (United Kingdom)

Dianyuan Fan, Shanghai Institute of Optics and Fine Mechanics (China)

Feng Zhang, Academy of Chinese Aerospace Science and Industry Feihang Technology (China)

Gaurav Sharma, University of Rochester (United States)

Guangjun Zhang, Beihang University (China)

Huitao Fan, Luoyang Optoelectro Technology Development Center (China)

Huixing Gong, Shanghai Institute of Technical Physics (China)

Jannick Rolland, University of Rochester (United States) and LighTopTech Corporation (United States)

Jianquan Yao, Tianjin University (China)

Jiaqi Wang, Changchun Institute of Optics, Fine Mechanics and Physics (China)

Jingshan Jiang, Center for Space Science and Applied Research (China)

Junhao Chu, Shanghai Institute of Technical Physics (China)

Lijun Wang, Changchun Institute of Optics, Fine Mechanics and Physics (China)

Lin Li, Laser Processing Research Centre, The University of Manchester (United Kingdom)

Liwei Zhou, Beijing Institute of Technology (China)

Ming C. Leu, Missouri University of Science and Technology (United States)

Norbert Kaiser, Fraunhofer Institute for Applied Optics and Precision Engineering (Germany)

Qifeng Yu, National University of Defense Technology (China)

Qingxi Tong, The Institute of Remote Sensing and Digital Earth (China)

Shouhuan Zhou, North China Research Institute of Electro-optics (China) 
Tianchu Li, National Institute of Metrology (China)

Ting-Chung Poon, Virginia Polytechnic Institute and State University (United States)

Wei Wang, Beijing Institute of Aerospace Control Devices (China)

Zuyan Xu, The Technical Institute of Physics and Chemistry (China)

Program Committee

Songlin Zhuang, Chair, University of Shanghai for Science and Technology (China)

Huaming Wang, Co-chair, Beihang University (China)

Huikai Xie, Co-chair, University of Florida (United States)

Jannick Rolland, Co-chair, University of Rochester (United States)

Jürgen Czarske, Co-chair, Technische Universität Dresden

(Germany)

Yongtian Wang, Co-chair, Beijing Institute of Technology (China)

Anatoli G. Borovoi, V.E. Zuev Institute of Atmospheric Optics

(Russian Federation)

Bincheng Li, Institute of Optics and Electronics (China)

Binghen Lu, Xi'an JiaoTong University (China)

Byoungho Lee, Seoul National University (Republic of Korea)

Changxiang Yan, Changchun Institute of Optics, Fine Mechanics and Physics (China)

Dae Wook Kim, The University of Arizona (United States)

David Webb, Aston University (United Kingdom)

Dawei Zhang, University of Shanghai for Science and Technology (China)

Dong Liu, Anhui Institute of Optics and Fine Mechanics (China)

Fugen Zhou, Beijing University of Aeronautics and Astronautics (China)

Gaurav Sharma, University of Rochester (United States)

Geert Verhaeghe, Faurecia Autositze GmbH (Germany)

Guangya Zhou, National University of Singapore (Singapore)

Haimei Gong, Shanghai Institute of Technical Physics (China)

Jin Lu, Tianjin Jinhang Institute of Technical Physics (China)

Jun Zhou, Shanghai Institute of Optics and Fine Mechanics (China)

Kai Cheng, Brunel University (United Kingdom)

Ligong Zheng, Changchun Institute of Optics Fine Mechanics and Physics (China)

Lijun Wang, Changchun Institute of Optics, Fine Mechanics and Physics, (China)

Lin Li, Laser Processing Research Centre, The University of Manchester (United Kingdom)

Ming C. Leu, Missouri University of Science and Technology (United States)

Minlin Zhong, Tsinghua University (China)

Mircea Guina, Tampere University of Technology (Finland) 
Norbert Kaiser, Fraunhofer Institute for Applied Optics and Precision Engineering (Germany)

Pu Wang, Beijing University of Technology (China)

Roland Winston, University of California (United States)

Rongbing W. B. Lee, The Hong Kong Polytechnic University (Hong Kong, China)

Shulian Zhang, Tsinghua University (China)

Ting-Chung Poon, Virginia Polytechnic Institute and State University (United States)

Wei Wang, Beijing Institute of Aerospace Control Devices (China)

Wenli Ma, The Institute of Optics and Electronics (China)

Yi Luo, Tsinghua University (China)

Yiqin Ji, Tianjin Jinhang Institute of Technical Physics (China)

Yong Bi, Academy of Opto-electronics (China)

Yong Cheng, Wuhan Ordnance Non-Commissioned Officers Academy (China)

Yongnian Yan, Jiangsu YONGNIAN Laser Forming Technology Company, Ltd. (China)

Zhichuan Niu, Institute of Semiconductors (China) 
Proc. of SPIE Vol. $9295929501-12$

Downloaded From: https://www.spiedigitallibrary.org/conference-proceedings-of-spie on 26 Apr 2023 Terms of Use: https://www.spiedigitallibrary.org/terms-of-use 


\title{
Conference Committee
}

\author{
Conference Chairs
}

Norbert Kaiser, Fraunhofer Institute for Applied Optics and Precision Engineering (Germany)

Bincheng Li, Institute of Optics and Electronics, CAS, (China)

Yiqin Ji, Tianjin Jinhang Institute of Technical Physics (China)

Geert Verhaeghe, Faurecia Autositze GmbH (Germany)

Minlin Zhong, Tsinghua University (China)

Bingheng Lu, Xi'an Jiaotong University (China)

Huaming Wang, Beihang University (China)

Ming C. Leu, Missouri University of Science and Technology (United States)

Yongnian Yan, Jiangsu Yongnian Laser Forming Technology Company, Ltd. (China)

Huikai Xie, University of Florida (United States)

Dawei Zhang, University of Shanghai for Science and Technology (China)

Guangya Zhou, National University of Singapore (Singapore) 
Proc. of SPIE Vol. $9295929501-14$

Downloaded From: https://www.spiedigitallibrary.org/conference-proceedings-of-spie on 26 Apr 2023 Terms of Use: https://www.spiedigitallibrary.org/terms-of-use 


\section{Introduction}

We had the great honor of organizing the International Symposium on Optoelectronic Technology and Application 2014 (IPTA 2014) in Beijing. It was truly a great pleasure for us to greet nearly 1,000 participants from many different countries attending IPTA 2014! We firmly believe that the symposium will become an important international event in the field of photoelectronic technology.

IPTA 2014 was sponsored by Chinese Society of Astronautics (CSA) and China Hightech Industrialization Association, technically co-sponsored by SPIE, and organized by Photoelectronic Technology Committee, Chinese Society of Astronautics. 27 cooperating organizations supported the conference. There were nearly 600 papers accepted for presentation at IPTA 2014, contributed by over 1078 authors from more than 10 countries, including United States, United Kingdom, Germany, France, Norway, Australia, Canada, Japan, Korea, Russia, and China. We had six plenary speeches and 228 well-known scientists and experts, from both home and abroad to give invited talks at different sessions.

The purpose of IPTA 2014 was to provide a forum for the participants to report and review innovative ideas, with up-to-date progress and developments, and discuss the novel approaches to application in the field of photoelectronic technology. We sincerely hope that the research and development in the optical and photoelectronic fields will be promoted, and international cooperation sharing the common interest will be enhanced.

On behalf the Organization Committee of IPTA 2014, we would like to heartily thank our sponsors and cooperating organizations for all they have done for the conference. We would also like to thank the authors for their contribution to the proceedings; the participants and friends of IPTA 2014, for their interest and efforts in helping us to make the symposium possible; and the Program Committee for their effective work and valuable advice, especially the IPTA 2014 Secretariat and the SPIE staff, for their tireless efforts and outstanding services in preparing the conference and publishing the Proceedings.

\section{Guofan Jin \\ Songlin Zhuang \\ IPTA 2014 Symposium Committee Chairs}


Proc. of SPIE Vol. 9295 929501-16

Downloaded From: https://www.spiedigitallibrary.org/conference-proceedings-of-spie on 26 Apr 2023 Terms of Use: https://www.spiedigitallibrary.org/terms-of-use 